\title{
Gas Phase Reactions of Carbon Cluster Ions with Crotononitrile
}

\author{
Jing Sun and Hans-Friedrich Grützmacher* \\ Fakultät für Chemie der Universität Bielefeld, \\ Postfach 100131, Universitätsstrasse, D-33615 Bielefeld, Germany
}

\begin{abstract}
Chava Lifshitz ${ }^{\dagger}$
Fritz Haber Research Center for Molecular Dynamics, Department of Physical Chemistry, The Hebrew University of Jerusalem, Jerusalem 91904, Israel
\end{abstract}

Received: November 16, 1993; In Final Form: February 14, $1994^{\circ}$

\begin{abstract}
Ion/molecule reactions of carbon cluster ions $\left(\mathrm{C}_{n}{ }^{++}, n=10-20\right)$ in the gas phase with crotononitrile (CRN) were investigated by Fourier transform ion cyclotron resonance spectrometry (FT-ICR). The carbon cluster ions studied were generated by electron impact ionization of perchlorinated aromatic compounds and subsequent elimination of all $\mathrm{Cl}$ substituents from the molecular ion. Clear pseudo-first-order reactions were observed for the carbon cluster ions $\mathrm{C}_{n}{ }^{++}$thus formed without any sign of isomeric clusters of different reactivity. AM1 calculations of the stability of $\mathrm{C}_{10} \mathrm{Cl}_{x}(x=4,6,8)$ derived from octachloronaphthalene indicate that the most stable monocyclic $\mathrm{C}_{n}{ }^{++}$are formed by this method. The reactions of $\mathrm{C}_{n}{ }^{++}$with $\mathrm{CRN}$ at a low operating pressure $\left(1.2 \times 10^{-8}-8.0 \times 10^{-7} \mathrm{mbar}\right)$ include the formation of adduct ions stabilized by radiative emission or/and loss of a neutral species ( $\mathrm{H}$ or $\mathrm{HCN})$ from the adduct ion. Rate constants for the reaction with $\mathrm{CRN}$ are distinctly larger than for the cluster reactions with $\mathrm{HCN}$ and acrylonitrile, and an exceptionally large reaction efficiency is found for $\mathrm{C}_{13}{ }^{\circ+}$ and $\mathrm{C}_{17^{\circ+}}$. This correlates inversely with the thermochemical stability of the carbon clusters. The nature of the reaction products depends on the $\mathrm{C}$ number of $\mathrm{C}_{n}{ }^{+}$. Consecutive reactions of the primary product ions $\mathrm{C}_{n+4} \mathrm{H}_{4} \mathrm{~N}^{+}$, formed by loss of $\mathrm{H}$ from the adduct ion, were observed only for reactions of even numbered $\mathrm{C}_{n}{ }^{++}$. On collision induced dissociation (CID) the adduct ions from $\mathrm{C}_{n}{ }^{++}(n=11,13)$ redissociate to the original cluster ion while the adduct ions of $\mathrm{C}_{17}{ }^{\circ+}$ lose $\mathrm{C}_{3}$ and $\mathrm{C}_{6}\left(2 \mathrm{C}_{3}\right)$. A reaction model explaining these observations is proposed.
\end{abstract}

\section{Introduction}

The structure and reactivity of the carbon cluster ions $\mathrm{C}_{n}{ }^{++}$ have attracted great interest during the last years. ${ }^{1}$ These studies have shown that small $\mathrm{C}_{n}{ }^{+}(n<10)$ are more reactive and undergo also different reactions than larger ones. ${ }^{2}$ The ion/molecule reactions of small $\mathrm{C}_{n}{ }^{++}$are characterized by a typical carbene reactivity toward organic molecules. ${ }^{2 a, 3}$ For example, the products reported by McElvany ${ }^{2 a}$ for the ion/molecule reactions of $\mathrm{C}_{n}{ }^{++}$ $(n<10)$ with methane, ethylene, and acetylene are explained by insertion into a $\mathrm{C}-\mathrm{H}$ bond or addition to the $\mathrm{C}-\mathrm{C} \pi$-bond followed by fragmentations of the resulting adduct ions. In the case of medium sized $\mathrm{C}_{n}{ }^{+}(n=10-23)$, however, a usually rather slow reaction yielding stable adduct ions by radiative stabilization becomes the most important process. Thus, the ion/molecule reactions of $\mathrm{C}_{n}{ }^{++}$with acetylene ${ }^{2 \mathrm{a}}(n=10-14)$ and $\mathrm{HCN}^{4}(n=$ $10,13)$ produce mainly adduct ions with small reaction efficiencies. Similarly, $\mathrm{C}_{n}{ }^{+}(n=10-23)$ and benzene ${ }^{5}$ as well as substituted benzenes and naphthalene ${ }^{6}$ yield adduct ions with an increased reaction efficiency, which is attributed to the increased lifetime of the collision complexes with these large substrates. In addition, loss of $\mathrm{H}$ from the adduct ions of these reactions is observed for some $\mathrm{C}_{n}{ }^{++}, 2 \mathrm{a}, 6$ This different reactivity of $\mathrm{C}_{n}{ }^{*+}$ toward neutral organic reactants is assigned to the different structures of small and medium sized $\mathrm{C}_{n}{ }^{+}$. Both theoretical calculations ${ }^{7}$ and experimental results $\mathrm{S}^{2,4,8}$ indicate a change from linear to monocyclic structures of neutral and ionized $C_{n}$ clusters at $n=9$ or 10. Thus, the carbenic end groups of the linear $\mathrm{C}_{n}{ }^{++}$are absent in the larger monocyclic $\mathrm{C}_{n}{ }^{-+}$, effecting the reduced reactivity of the latter ions.

Recently, we have shown that the reaction of $\mathrm{C}_{n}{ }^{++}(n=10-20)$ with acrylonitrile (ACN) 9yields also adduct ions $\mathrm{C}_{n+3} \mathrm{H}_{3} \mathrm{~N}^{\bullet+}$ as

* Corresponding author.

+ Archie and Majorie Sherman Professor of Chemistry.

- Abstract published in Advance ACS Abstracts, April 1, 1994.

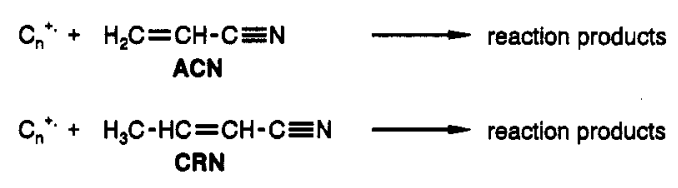

the sole product, again very likely by radiative stabilization. However, for $n=10$ and 13 the rates of these ion/molecule reactions are about 100 times larger than those with $\mathrm{HCN}$. In addition, not only $\mathrm{C}_{13} 3^{\text {++ }}$ but also $\mathrm{C}_{17}{ }^{\text {++ }}$ shows a particularly large reactivity. These results demonstrate that medium sized monocyclic carbon cluster ions may exhibit a significant reactivity toward organic molecules besides arenes. Evidently, the reactivity of the monocyclic $\mathrm{C}_{n}{ }^{++}$depends on their thermodynamic stability and electronic configuration. For example, the especially low ionization energies of $\mathrm{C}_{n}$ with $n=(4 m+3)$ have been explained by an aromatic $(4 m+2)$ configuration of the valence electrons of the corresponding cluster ions. ${ }^{10}$ Accordingly, the cluster ions $\mathrm{C}_{13}$ and $\mathrm{C}_{17}(n=4 m+1)$ are anti-aromatic species, which would explain their increased reactivity. In this paper, we report the ion/molecule reactions of $\mathrm{C}_{n}{ }^{++}, n=10-20$, with crotononitrile (CRN) to explore further the reactivity of medium sized carbon cluster ions of monocyclic structure. It will be shown that $\mathrm{C}_{13}{ }^{\circ+}$ and $\mathrm{C}_{17^{\circ+}}$ are again distinguished from their neighboring cluster ions by an increased reactivity for the generation of adduct ions, paralleling the results obtained with $\mathrm{ACN}$. However, contrary to the reaction with $A C N$, the adduct ions formed by the reaction of cluster ions $\mathrm{C}_{n}{ }^{+}+$with an odd and an even number of $\mathrm{C}$ atoms, respectively, with CRN exhibit a different gas phase chemistry.

\section{Experimental Section}

Crotononitrile (CRN) is available commercially (Merck, purity $>99 \%$ ) and was used without further purification. The carbon cluster ions studied were generated by electron impact ionization of the appropriate perchlorinated aromatic compound (Figure 1) 
<smiles>ClC1=C(Cl)C(Cl)(Cl)c2c(Cl)c(Cl)c(Cl)c(Cl)c2C1(Cl)Cl</smiles>

1<smiles>Clc1c(Cl)c(Cl)c2c(c1Cl)-c1c(Cl)c(Cl)c(Cl)c(Cl)c1C(Cl)(Cl)C2(Cl)Cl</smiles>

5<smiles>Clc1c(Cl)c(Cl)c2c(c1Cl)-c1c(c(Cl)c3c(Cl)c(Cl)c(Cl)c(Cl)c3c1Cl)C2(Cl)Cl</smiles><smiles>FC(F)(Cl)c1c(Cl)c(Cl)c2c(Cl)c(Cl)c(Cl)c(Cl)c2c1Cl</smiles><smiles>Clc1c(Cl)c2cc(Cl)c3c(Cl)c(Cl)c(Cl)c4c(Cl)c(Cl)c(c1Cl)c2c34</smiles>

6<smiles>Clc1c(Cl)c2c3c(c(Cl)c(Cl)c(Cl)c3c1Cl)C(Cl)(Cl)C2(Cl)Cl</smiles><smiles>Clc1c(Cl)c(Cl)c2c(c1Cl)-c1c(Cl)c(Cl)c(Cl)c(Cl)c1C2(Cl)Cl</smiles><smiles>Clc1c(Cl)c2c(Cl)c(Cl)c3c(Cl)c(Cl)c(Cl)c4c(Cl)c(Cl)c(c1Cl)c2c34</smiles>

7<smiles></smiles>

10

Figure 1. Precursor compounds for the generation of the carbon cluster ions $\mathrm{C}_{n}{ }^{++}$.

and subsequent exhaustive chlorine elimination from the resulting molecular ions in the external ion source ${ }^{11}$ of a Bruker CMS 47X FT-ICR spectrometer ${ }^{12}$ equipped with a $4.7-\mathrm{T}$ superconducting magnet.

The details of the preparation of the compounds, of the generation of the carbon cluster ions, and of the determination of the rate constants of their ion/molecule reactions have been described before. ${ }^{9}$ Briefly, following the electron impact induced ionization $(70 \mathrm{eV})$ and fragmentation of the perchlorinated arenes in the external ion source, all ions were transferred into the FTICR cell, and the carbon cluster ions $\mathrm{C}_{n}{ }^{*+}$ were isolated according to their exact mass using high resolution resonance frequency ejection techniques, as described elsewhere. ${ }^{9}$ Special care was taken to cool the isolated $\mathrm{C}_{n}{ }^{\circ+}$ to ambient temperature by admitting a pressure pulse of argon to the FT-ICR cell.

The ion/molecule reactions of the more reactive $\mathrm{C}_{n}{ }^{++}$with the neutral CRN were studied at a constant partial pressure of typically $(1.2-5.0) \times 10^{-8} \mathrm{mbar}$, but a partial pressure up to 8.0 $\times 10^{-7}$ mbar had to be used for reactions of low efficiency. Transient signals were averaged for up to 100 experimental cycles prior to performing the Fourier transformation. The rate constants were determined by observing the decay of the intensity of the ions $\mathrm{C}_{n}{ }^{++}$relative to the product ions as a function of the reaction time. With the exception of the very slow reactions the process was followed until about $80-90 \%$ of the respective $\mathrm{C}_{n}{ }^{++}$ had reacted, and good pseudo-first-order kinetics were observed in all cases. The bimolecular rate constants $k_{\mathrm{bi}}$ were calculated by taking into account the partial pressure of CRN. The ion gauge was calibrated as discussed previously. ${ }^{9}$ The rate constants reported are accurate within $20 \%$. The branching ratio of the primary reactions was calculated from the ratios of product ion intensities during the initial period of the reaction. For secondary reactions the branching ratio was obtained by using the relevant ion intensities of the reaction at the end of the reaction. The maximal estimated uncertainty of the branching ratios thus obtained corresponds to $\pm 20 \%$.

The collision induced decomposition (CID) of the product ions of the ion/molecule reaction of $\mathrm{C}_{n}{ }^{+}$with CRN was studied as described previously $y^{9}$ by isolating the respective product ion using the ion ejection facilities of the FT-ICR mass spectrometer, admitting argon into the ICR cell, and accelerating the ions by irradiation with the appropriate cyclotron frequency until about $50 \%$ of the product ions were fragmented.
TABLE 1: Primary Products, Rate Constants, $k_{\mathrm{b}}$, and Reaction Efficiencies of the Bimolecular Reactions of $\mathrm{C}_{\boldsymbol{}^{-}}{ }^{+}$ with CRN

\begin{tabular}{|c|c|c|c|c|c|c|}
\hline \multirow{2}{*}{\multicolumn{2}{|c|}{ educt }} & \multicolumn{3}{|c|}{ products } & \multirow[b]{3}{*}{$10^{11} k_{\mathrm{bj}}{ }^{a}$} & \multirow[b]{3}{*}{ efficiency } \\
\hline & & \multirow[b]{2}{*}{$m / z$} & \multirow{2}{*}{$\begin{array}{c}\text { ion + neutral } \\
\text { species }\end{array}$} & \multirow{2}{*}{$\begin{array}{l}\text { branching } \\
\text { ratio }\end{array}$} & & \\
\hline$m / z$ & ion & & & & & \\
\hline 120 & $\mathrm{C}_{10^{\circ+}}$ & $\begin{array}{l}187 \\
186 \\
160\end{array}$ & $\begin{array}{l}\mathrm{C}_{14} \mathrm{H}_{5} \mathrm{~N}^{\bullet+} \\
\mathrm{C}_{14} \mathrm{H}_{4} \mathrm{~N}^{+}+\mathrm{H}^{\bullet} \\
\mathrm{C}_{13} \mathrm{H}_{4}{ }^{++}+\mathrm{HCN}\end{array}$ & $\begin{array}{l}0.17 \\
0.58 \\
0.25\end{array}$ & 11 & 34.5 \\
\hline 132 & $\mathrm{C}_{11^{\prime+}}$ & 199 & $\mathrm{C}_{15} \mathrm{H}_{5} \mathrm{~N}^{\circ+}$ & 1 & 33 & 10.2 \\
\hline 144 & $\mathrm{C}_{12}{ }^{\circ+}$ & $\begin{array}{l}211 \\
210\end{array}$ & $\begin{array}{l}\mathrm{C}_{16} \mathrm{H}_{5} \mathrm{~N}^{++} \\
\mathrm{C}_{16} \mathrm{H}_{4} \mathrm{~N}^{+}+\mathrm{H}^{\bullet}\end{array}$ & $\begin{array}{l}0.72 \\
0.28\end{array}$ & 120 & 39.2 \\
\hline 156 & $\mathrm{C}_{13^{\circ+}}$ & 223 & $\mathrm{C}_{17} \mathrm{H}_{5} \mathrm{~N}^{*+}$ & 1 & 120 & 39.7 \\
\hline 168 & $\mathrm{C}_{14^{\circ+}}$ & & & & $<0.1$ & $<0.03$ \\
\hline 180 & $\mathrm{C}_{15^{\circ+}}$ & & & & $<0.1$ & $<0.03$ \\
\hline 192 & $\mathrm{C}_{16^{\circ+}}$ & & & & $<0.1$ & $<0.03$ \\
\hline 204 & $\mathrm{C}_{17^{\circ+}}$ & 271 & $\mathrm{C}_{21} \mathrm{H}_{5} \mathrm{~N}^{\bullet+}$ & 1 & 86 & 29.6 \\
\hline 216 & $\mathrm{C}_{18}{ }^{\circ+}$ & & & & $<0.1$ & $<0.03$ \\
\hline 240 & $\mathrm{C}_{20^{\circ}}+$ & & & & $<0.1$ & $<0.03$ \\
\hline
\end{tabular}

${ }^{a}$ In molecule $\cdot \mathrm{cm}^{-3} \cdot \mathrm{s}^{-1}$; mean error $\pm 20 \% .{ }^{b}$ In percent.

TABLE 2: Products and Branching Ratios of the Reactions of the (Adduct - $\mathrm{H}$ ) Ion $\mathrm{C}_{\boldsymbol{w}+4} \mathrm{H}_{4} \mathrm{~N}^{+}$

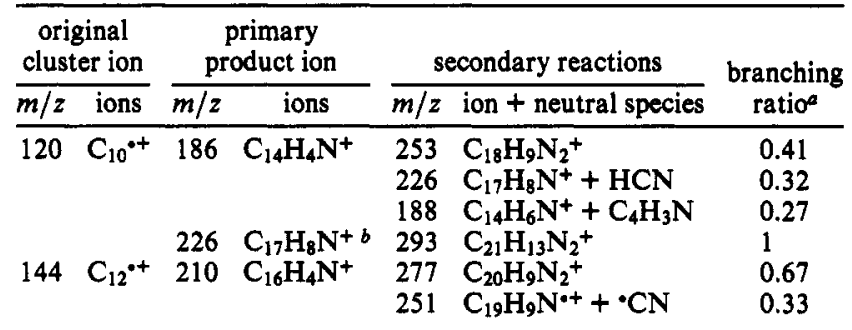

a Maximal estimated uncertainty $\pm 20,{ }^{b}$ Tertiary reaction.

\section{Results}

The rate constants, $k_{\mathrm{bi}}$, reaction efficiencies, and products of the ion/molecule reactions of $\mathrm{C}_{n}{ }^{++}(n=10-20)$ with crotononitrile (CRN) are shown in Tables 1 and 2 .

All kinetic curves, obtained by plotting the relative intensity of $\mathrm{C}_{n}{ }^{*+}$ vs the reaction time, correspond to a monoexponential decay. Thus, no indication of the formation of isomeric carbon cluster ions is obtained. As an example, the experimental intensity curves of educt and product ions of the reaction of $\mathrm{C}_{12}{ }^{*+}$ and CRN are shown in Figure 2. 


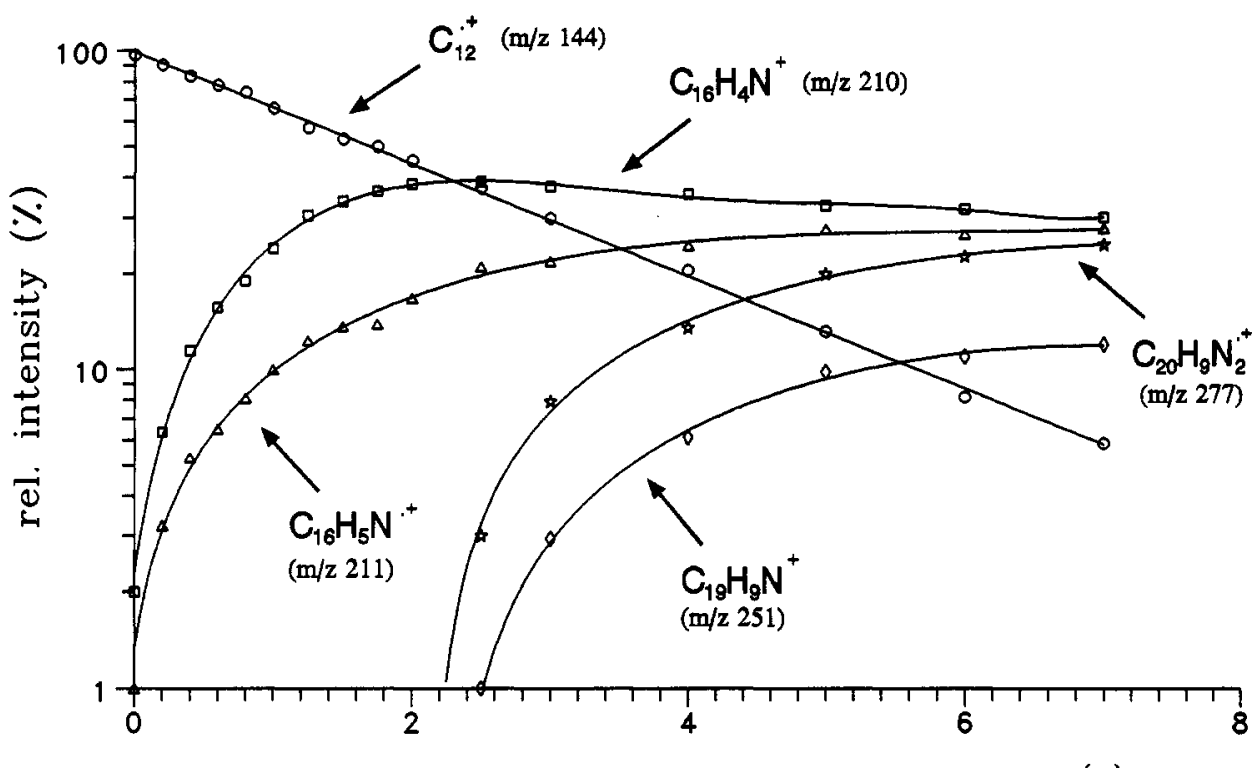

$t(s)$

Figure 2. Kinetic curves for the reaction of $\mathrm{C}_{12}{ }^{\circ+}$ and CRN $\left(p=1.6 \times 10^{-8} \mathrm{mbar}\right)$.

The $k_{\mathrm{bi}}$ for the reactions of $\mathrm{C}_{10^{*+}}, \mathrm{C}_{11^{*+}}, \mathrm{C}_{12}{ }^{*+}$, and $\mathrm{C}_{17^{*+}}$ with $C R N$ are quite large, and the efficiencies of reactions with $C R N$ are generally larger than the efficiencies of corresponding reactions with $\mathrm{HCN}^{4}$ and $\mathrm{ACN} .9$ No product ions were observed for the reactions of the other $\mathrm{C}_{n}{ }^{++}(n=14-16,18,20)$ under the present conditions. Thus, only the upper limits of $k_{\mathrm{bi}}$ estimated for these reactions by taking into account the respective partial pressure of CRN are given in Table 1. Analogous to the reaction with ACN the cluster ions $\mathrm{C}_{13^{\circ+}}$ and $\mathrm{C}_{17}{ }^{\circ+}$ exhibit an increased reactivity compared to the neighboring $\mathrm{C}_{n}{ }^{++}$, although $\mathrm{C}_{12}{ }^{++}$is also rather reactive toward $\mathrm{CRN}$. In contrast, the reaction efficiency of $\mathrm{C}_{11}{ }^{++}$is clearly smaller than that of its neighbors.

While the reactions of the carbon cluster ions with $A C N$ yield only adducts, ${ }^{9}$ the product ions formed by the reaction of $\mathrm{C}_{n}{ }^{++}$ with $\mathrm{CRN}$ depend on the number of $\mathrm{C}$ atoms in $\mathrm{C}_{n}{ }^{++}$. In the case of odd numbered $\mathrm{C}_{n}{ }^{++}$only adduct ions $\mathrm{C}_{n+4} \mathrm{H}_{5} \mathrm{~N}^{\cdot+}(n=11,13$ and 17) are formed, very likely by radiative stabilization of the collision complex. This is substantiated for $\mathrm{C}_{13^{*}}{ }^{*+}$ by measurements of $k_{\mathrm{bi}}$ at different partial pressures $\left(1.2 \times 10^{-8}-8.0 \times 10^{-7} \mathrm{mbar}\right)$ of CRN, since the $k_{\mathrm{bi}}$ obtained are independent of the partial pressure of the CRN within experimental error. The reactions of the even numbered $\mathrm{C}_{n}{ }^{++}$are more complicated. Besides formation of the adduct $\mathrm{C}_{n+4} \mathrm{H}_{5} \mathrm{~N}^{\bullet+}(n=10$ and 12$)$, other product ions are observed, formed by loss of neutral species from the collision complex. Furthermore, secondary and even tertiary reactions of the primary product ions with $C R N$ are observed (Table 2). For example, the reaction $\mathrm{C}_{12}{ }^{\circ+}$ with $\mathrm{CRN}$ provides $\mathrm{C}_{16} \mathrm{H}_{5} \mathrm{~N}^{+}(m / z 211)$ and $\mathrm{C}_{16} \mathrm{H}_{4} \mathrm{~N}^{+}(m / z 210)$ as primary product ions by parallel reactions, as shown clearly by the intensity curves (Figure 2). The latter ions, which are formed by loss of an $\mathrm{H}$ atom from the adduct, react further with $\mathrm{CRN}$, yielding the secondary product ions $\mathrm{C}_{20} \mathrm{H}_{9} \mathrm{~N}_{2}+(m / z 277)$ and $\mathrm{C}_{19} \mathrm{H}_{9} \mathrm{~N}^{\bullet+}(m / z$ 251), The reaction of $\mathrm{C}_{10^{\circ}}{ }^{+}$is even more complicated. Firstly, the reaction of $\mathrm{C}_{10^{\circ+}}$ with CRN produces three primary product ions: adduct ions $\mathrm{C}_{14} \mathrm{H}_{5} \mathrm{~N}^{+}(m / z 187)$, ions $\mathrm{C}_{14} \mathrm{H}_{4} \mathrm{~N}^{+}(m / z 186)$ formed by loss of an $\mathrm{H}$ atom from the adduct, and ions $\mathrm{C}_{13} \mathrm{H}_{4}{ }^{++}$ $(m / z 160)$ formed by loss of HCN. Secondly, the primary product ions $\mathrm{C}_{14} \mathrm{H}_{4} \mathrm{~N}^{+}$react further with $\mathrm{CRN}$ to yield the secondary product ions $\mathrm{C}_{14} \mathrm{H}_{6} \mathrm{~N}^{+}(m / z 188), \mathrm{C}_{17} \mathrm{H}_{8} \mathrm{~N}^{+}(m / z 226)$, and $\mathrm{C}_{18} \mathrm{H}_{9} \mathrm{~N}_{2}{ }^{++}(m / z 253)$. Then, the secondary product ions $\mathrm{C}_{17} \mathrm{H}_{8} \mathrm{~N}^{+}$react again with $\mathrm{CRN}$, generating tertiary product ions $\mathrm{C}_{21} \mathrm{H}_{13} \mathrm{~N}_{2}^{+}(m / z 293)$.

Further information about the structures of the product ions was obtained by CID of the primary adduct ions $\mathrm{C}_{15} \mathrm{H}_{5} \mathrm{~N}^{\cdot+}$, $\mathrm{C}_{17} \mathrm{H}_{5} \mathrm{~N}^{\circ+}$, and $\mathrm{C}_{21} \mathrm{H}_{5} \mathrm{~N}^{\circ+}$ formed by the cluster ions $\mathrm{C}_{11}{ }^{\circ+}, \mathrm{C}_{13}{ }^{\circ+}$,
TABLE 3: CID Spectra of Some Product Ions from the Reactions of $\mathrm{C}_{n}^{++}$with CRN

\begin{tabular}{|c|c|c|c|c|c|c|}
\hline $\begin{array}{l}\text { original } \\
\text { cluster } \\
\text { ion }\end{array}$ & $m / z$ & product ion & $m / z$ & $\begin{array}{c}\text { CID } \\
\text { fragment ions }+ \\
\text { neutral species }\end{array}$ & $m / z$ & $\begin{array}{c}\text { \% rel } \\
\text { int }\end{array}$ \\
\hline $\begin{array}{l}\mathrm{C}_{11^{\circ+}} \\
\mathrm{C}_{12^{\circ+}} \\
\mathrm{C}_{13^{\circ+}} \\
\mathrm{C}_{17^{\circ+}}\end{array}$ & $\begin{array}{l}132 \\
144 \\
156 \\
204\end{array}$ & $\begin{array}{l}\mathrm{C}_{15} \mathrm{H}_{5} \mathrm{~N}^{\bullet+} \\
\mathrm{C}_{16} \mathrm{H}_{4} \mathrm{~N}^{+} \\
\mathrm{C}_{17} \mathrm{H}_{5} \mathrm{~N}^{\bullet+} \\
\mathrm{C}_{21} \mathrm{H}_{5} \mathrm{~N}^{\bullet+}\end{array}$ & $\begin{array}{l}199 \\
210 \\
223 \\
271\end{array}$ & 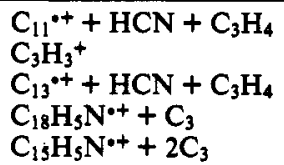 & $\begin{array}{r}132 \\
39 \\
156 \\
235 \\
199\end{array}$ & $\begin{array}{r}100 \\
100 \\
100 \\
75 \\
25\end{array}$ \\
\hline
\end{tabular}

and $\mathrm{C}_{17^{\circ+}}$, respectively, and the primary product ion $\mathrm{C}_{16} \mathrm{H}_{4} \mathrm{~N}^{+}$ generated in the reaction of $\mathrm{C}_{12}{ }^{*+}$ with $\mathrm{CRN}$ by loss of $\mathrm{H}$ (Table 3). It is necessary to perform the CID experiments at a low constant pressure of CRN to avoid predominant proton transfer and charge exchange of kinetically excited product ions with CRN during CID. Because of this experimental limitation the product ion intensity in the corresponding mass spectra is small for the less reactive $\mathrm{C}_{n}{ }^{+}$and for reactions giving multiple products even at long reaction times. Therefore, a CID study of the product ions of $\mathrm{C}_{n}{ }^{+}(n=10,14-16,18,20)$ was not possible.

The kind of CID fragment ions depends on the size of the adduct ions. The CID of the adduct ions $\mathrm{C}_{15} \mathrm{H}_{5} \mathrm{~N}^{\bullet+}$ and $\mathrm{C}_{17} \mathrm{H}_{5} \mathrm{~N}^{\bullet+}$ (derived from $\mathrm{C}_{n}{ }^{*+}, n=11$ and 13 , respectively) induces backdissociation into the original cluster ions $\mathrm{C}_{n}{ }^{\circ+}$ and $\mathrm{C}_{4} \mathrm{H}_{5} \mathrm{~N}(\mathrm{CRN}$ or probably to propyne, $\mathrm{C}_{3} \mathrm{H}_{4}$, and $\mathrm{HCN}$ as more stable neutral fragments). However, $\mathrm{CID}$ of the adduct ion $\mathrm{C}_{21} \mathrm{H}_{5} \mathrm{~N}^{\cdot+}$ (derived from $\mathrm{C}_{17^{\circ+}}$ ) leads to dissociation into the fragment ions $\mathrm{C}_{18} \mathrm{H}_{5} \mathrm{~N}^{\bullet+}$ $(m / z 235)$ and $\mathrm{C}_{15} \mathrm{H}_{5} \mathrm{~N}^{\circ+}(m / z 199)$ by loss of $\mathrm{C}_{3}$ and $\mathrm{C}_{6}$ (or $2 \mathrm{C}_{3}$ ), respectively. These CID fragmentation patterns are analogous to those observed for the adduct ions $\mathrm{C}_{n+3} \mathrm{H}_{3} \mathrm{~N}^{\bullet+}$ from the reactions of $\mathrm{C}_{n}{ }^{++}$with $\mathrm{ACN} .{ }^{9}$ In particular, no loss of $\mathrm{CN}$ or $\mathrm{HCN}$ is observed. The CID of the product ion $\mathrm{C}_{16} \mathrm{H}_{4} \mathrm{~N}^{+}$, formed during reaction of $\mathrm{C}_{12}{ }^{\circ+}$ with $\mathrm{CRN}$ by loss of an $\mathrm{H}$ atom, results in the formation of the fragment ion $\mathrm{C}_{3} \mathrm{H}_{3}{ }^{+}$only.

\section{Discussion}

Formation of Carbon Cluster Ions. A priori no direct evidence about the structure of the studied $\mathrm{C}_{n}{ }^{++}$is available. Theoretical calculations ${ }^{7 \mathrm{~d}}$ and experimental evidence ${ }^{13,14}$ agree that a monocyclic structure is the most stable one for the neutral and ionized $\mathrm{C}_{n}$ with $n=10-20$, which are studied here. However, it is possible that polycyclic isomers of $C_{n}$ may be generated from suitable precursors and that these high energy isomers may survive in the gas phase long enough to be detected by a special reactivity during 
SCHEME 1: Structures and Fragmentation of Some $\mathrm{C}{ }_{10} \mathrm{Cl}_{x}{ }^{+}$Ions $(x=8,7,6,4)$ Derived from Octachloronaphthalene

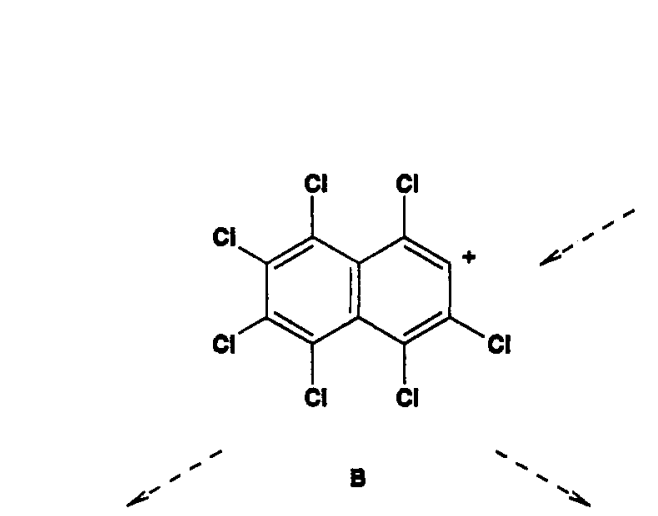<smiles>Clc1c(Cl)c(Cl)c2c(Cl)c(Cl)c(Cl)c(Cl)c2c1Cl</smiles><smiles>Clc1[c-]c(Cl)c2c(Cl)cc(Cl)c(Cl)c2c1Cl</smiles><smiles>Clc1c#cc2c(Cl)c(Cl)c(Cl)c(Cl)c2c1Cl</smiles><smiles>ClC#Cc1c(Cl)c(Cl)c(Cl)c(Cl)c1C#CCl</smiles>

A<smiles>Clc1c(Cl)c(Cl)c2c(Cl)c(Cl)c(Cl)c(Cl)c2c1Cl</smiles>

a<smiles>CCC</smiles>

fragmentution

of the carbon skeleton

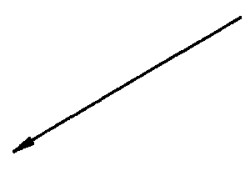

D<smiles></smiles>

E<smiles></smiles>

H<smiles>CC(C)C(C)O</smiles>

TABLE 4: Calculated Heat of Formation (by AM1) of Some $\mathrm{C}_{10} \mathrm{Cl}_{\mathrm{x}}$ Ions $(x=8,7,6,4)$, Derived from Octachloronaphthalene generation of $\mathrm{C}_{n}{ }^{+}+$from polychlorinated aromatic precursors was that the structure of the precursor could survive the electron impact induced ionization and fragmentation processes leading to a "memory effect" for resulting $\mathrm{C}_{n}{ }^{++}$, no unusual kinetic effects were observed during the ion/molecule reactions of these cluster ions. In particular, the reactions with $\mathrm{ACN}^{9}$ and $\mathrm{CRN}$ are strictly pseudo-first-order with a single rate constant, as expected for reactions of a uniform ensemble of cluster ions. It appears likely that these ions are the most stable ones formed from the energy rich isomers in view of the large energy necessary to eliminate completely all chloro substituents from the precursor molecular ions. Thus, monocyclic $\mathrm{C}_{n}{ }^{++}$are formed from the perchlorinated polycyclic precursors shown in Figure 1 by the electron impact induced $\mathrm{Cl}$ elimination, and obviously, considerable rearrangement of the carbon skeleton accompanies the mass spectrometric fragmentation of these compounds.

The EI mass spectra of the perchlorinated arenes are characterized by series of intense fragment ion peaks connected by losses of apparently $\mathrm{Cl}_{2}$ from the molecular ion and fragment ions. ${ }^{13}$ A study of the decomposition of metastable ions shows that the elimination of $\mathrm{Cl}_{2}$ arises from fast consecutive losses of two $\mathrm{Cl}$ atoms. Obviously, the structures of fragment ions generated by losses of two $\mathrm{Cl}$ substituents are especially stable, and somewhere in this series of fragment ions the transition from the polycyclic structure of the precursor to the monocyclic structure of the final carbon cluster ion must occur. To get some insight into this rearrangement in the case of octachloronaphthalene $\mathrm{C}_{10} \mathrm{Cl}_{8}$, the heats of formation of the corresponding ions $\mathrm{C}_{10} \mathrm{Cl}_{x}(x=8,7,6,4)$ were calculated by the semiempirical AM1 technique ${ }^{14}$ using the UHF method. The results are presented in Table 4 and Scheme 1.

\begin{tabular}{ccc}
\hline ion & & $\Delta H_{\mathrm{f}}(\mathrm{kcal} / \mathrm{mol})$ \\
\hline $\mathrm{C}_{10} \mathrm{Cl}_{8}$ & $\mathrm{M}$ & 214.6 \\
$\mathrm{C}_{10} \mathrm{Cl}_{7}$ & $\mathrm{~A}$ & 265.0 \\
& $\mathrm{~B}$ & 269.3 \\
$\mathrm{C}_{10} \mathrm{Cl}_{6}$ & $\mathrm{C}$ & 322.7 \\
& $\mathrm{D}$ & 300.5 \\
& $\mathrm{E}$ & 313.4 \\
& $\mathrm{~F}$ & 367.0 \\
$\mathrm{C}_{10} \mathrm{Cl}_{4}$ & $\mathrm{G}$ & 326.5 \\
& $\mathrm{H}$ & 423.5 \\
& $\mathrm{I}$ & 446.8
\end{tabular}

The initial loss of a $\mathrm{Cl}$ substituent from the $\alpha$-position of the octachloronaphthalene radical cation is favored, but not the subsequent loss of the adjacent $\mathrm{Cl}$ substituent leading to $o$-aryne derivatives. Instead, the elimination of the second $\mathrm{Cl}$ atom from position 4 or 5 yields particularly stable ions $\mathrm{C}_{10} \mathrm{Cl}_{6}{ }^{\circ+}$. In both cases the resulting $\mathrm{C}_{10} \mathrm{Cl}_{6}{ }^{*+}$ ions with the carbon skeleton of naphthalene are unstable and the loss of the second $\mathrm{Cl}$ is accompanied by a retro-Bergmann cyclization, ${ }^{15}$ giving rise to ions $\mathrm{D}$ and $\mathrm{E}$ derived from $o$-diethynylbenzene and [10] annulene, respectively. Further loss of $\mathrm{Cl}$ atoms from ion $\mathrm{E}$ leaves the macrocyclic carbon ring intact, while ion $\mathrm{D}$ decomposes, likely by $\mathrm{C}-\mathrm{C}$ cleavages, into smaller fragment ions. Thus, only the monocyclic structure survives the fragmentation processes, yielding eventually monocyclic $\mathrm{C}_{n}{ }^{\circ+}$. This picture of the generation of carbon cluster ions by exhaustive dechlorination of the molecular ions of perchlorinated polycyclic arenes gives also a plausible explanation for the observation that only polycyclic arenes of a "compact" structure product a satisfactory amount 
of carbon cluster ions in their EI mass spectra. Obviously, the generation of fragment ions capable of ring enlargement by a retro-Bergmann cyclization early in the sequence of $\mathrm{Cl}$ losses is essential for intense $\mathrm{C}_{n}{ }^{*+}$ formation.

Reactions of Carbon Cluster Ions. Theoretical calculations ${ }^{7 d}$ and experimental results ${ }^{16,17}$ show that in the series of linear $\mathrm{C}_{n}{ }^{++}$ with $n<10$ the thermodynamic stability of the ions alters between odd and even numbered carbon cluster ions while for monocyclic $\mathrm{C}_{n}{ }^{++}$with $n>10$ an "aromatic periodicity" is observed. Thus, the cluster ions $\mathrm{C}_{4 m+3^{\circ+}}\left(\mathrm{C}_{11}{ }^{\circ+}, \mathrm{C}_{15^{\circ+}}\right.$, etc. $)$ exhibit exceptional stability while cluster ions of the series $\mathrm{C}_{4 m+1}{ }^{{ }^{+}}\left(\mathrm{C}_{13}{ }^{++}, \mathrm{C}_{17}{ }^{+*}\right.$, etc.) are less stable than the neighboring carbon cluster ions. In this series monocyclic $\mathrm{C}_{10^{\circ}}{ }^{\circ}$ is probably a borderline case with unique properties. A comparison of the reactivities of the monocyclic $\mathrm{C}_{n}{ }^{+}$toward CRN and their thermodynamic stabilities shows that the less stable $\mathrm{C}_{n}{ }^{0+}$ are more reactive toward the neutral reactant, an effect that has also been observed for the reaction of $\mathrm{C}_{n}{ }^{++}$with $\mathrm{ACN} .{ }^{9}$ These results support the suggestion that the stability and the reactivity of medium sized carbon cluster ions $\mathrm{C}_{n}{ }^{+}$depend on the configuration of their delocalized $\pi$-electron system which may be either aromatic or anti-aromatic. Thus, the stability of the aromatic $\mathrm{C}_{n}{ }^{++}$with $4 m+3 \mathrm{C}$ atoms ions should coincide with a low reactivity. For the reaction with $A C N$ and CRN this expectation is confirmed clearly only by the first member of the aromatic series, $\mathrm{C}_{11^{+*}}$, exhibiting a reduced reactivity compared to the neighboring $\mathrm{C}_{n}{ }^{+}$. No reactions were observed for the next aromatic cluster ion $\mathrm{C}_{15^{*}}{ }^{\circ}$, but this is also true for its neighbors $\mathrm{C}_{14^{++}}$and $\mathrm{C}_{16^{++}}$. However, the expected high reactivity of the anti-aromatic $\mathrm{C}_{n}{ }^{++}$with $4 n+1 \mathrm{C}$ atoms is seen for $\mathrm{C}_{13}{ }^{+}$and $\mathrm{C}_{17^{+}}$, which have clearly a higher reactivity toward the unsaturated nitriles than their neighboring carbon cluster ions.

Compared to that with $\mathrm{HCN}^{4}$ and $\mathrm{ACN},{ }^{9}$ a distinctly higher reactivity of $\mathrm{C}_{n}{ }^{+}$toward $\mathrm{CRN}$ is observed. At least two explanations can be given for this effect. Firstly, the increased number of degrees of freedom of the collision complex with CRN causes an increased lifetime. It is known ${ }^{18-20}$ that the efficiencies of radiative stabilization of activated collision complexes of ion/ molecule reactions increase with the degrees of freedom. Secondly, however, the ionization energy (IE) of CRN (IE = $10.2 \mathrm{eV}^{21}$ ) is lower than that of $\mathrm{ACN}$ (IE $=10.9 \mathrm{eV}^{21}$ ) and $\mathrm{HCN}$ $\left(I E=13.6 \mathrm{eV}^{21}\right)$. Theoretical reactivity models ${ }^{22}$ and experimental results show ${ }^{23}$ that rate constants for nucleophilic addition reactions of radical cations of arenes in the gas phase decrease with the IE difference between the reactants. As will be discussed elsewhere, ${ }^{24}$ this appears to be also the case for the reactions of monocyclic $\mathrm{C}_{n}{ }^{+}$with electron rich substrates, thus displaying the characteristics of nucleophilic additions of arene radical cations.

Structures and Reactions of Product Ions. The structure of the adduct $\mathrm{C}_{n+4} \mathrm{H}_{5} \mathrm{~N}^{*+}$ of monocyclic $\mathrm{C}_{n}{ }^{*+}$ and unsaturated nitriles is not obvious. The dissociation of these product ions $\mathrm{C}_{n+4} \mathrm{H}_{5} \mathrm{~N}^{\bullet+}$ ( $n=11$ and 13) into the original reactants during the CID could indicate only a weak electrostatic attachment of CRN to the $\mathrm{C}_{n}{ }^{*+}$. However, the elimination of neutral $\mathrm{C}_{3}$ from the product ion $\mathrm{C}_{17} \mathrm{H}_{5} \mathrm{~N}^{\bullet+}$ during $\mathrm{CID}$ under identical conditions evidences a strong and probably covalent bond between $\mathrm{CRN}$ and the cluster ions. The loss of $C_{3}$ by collisional activation is well-known for larger $\mathrm{C}_{n}{ }^{\circ+}$, and apparently elimination of $\mathrm{C}_{3}$ and $\mathrm{CRN}$ (or the more stable fragments $\mathrm{C}_{3} \mathrm{H}_{4}$ and $\mathrm{HCN}$, respectively) from the product ions competes during CID and is dependent on the size of $\mathrm{C}_{n}{ }^{\circ+}$. This would indicate covalent bonding of $\mathrm{CRN}$ to the $\mathrm{C}_{n}{ }^{++}$studied. Furthermore, the CID of product ions $\mathrm{C}_{16} \mathrm{H}_{4} \mathrm{~N}^{*+}$ generated by loss of $\mathrm{H}$ from the adduct of $\mathrm{C}_{12}{ }^{\circ+}$ and $\mathrm{CRN}$ produces stable ions $\mathrm{C}_{3} \mathrm{H}_{3}{ }^{+}$only. The formation of this stable ion by CID is observed also for the product ions of the reactions of $\mathrm{C}_{n}{ }^{+}$with unsaturated hydrocarbons. Clearly, at least the structure of this product ion arises from a rearrangement of the initial direct adduct by $\mathrm{H}$ migrations.

Interestingly, the nature of the product ions, formed by reaction of $\mathrm{C}_{n}{ }^{+}$with CRN, alternates for even and odd numbered $\mathrm{C}_{n}{ }^{++}$ (Table 2). While odd numbered $\mathrm{C}_{n}{ }^{++}$yield only adduct ions with $\mathrm{CRN}$, as in the case of $\mathrm{ACN}$, even numbered $\mathrm{C}_{n}{ }^{*+}$ form additional product ions $\mathrm{C}_{n+4} \mathrm{H}_{4} \mathrm{~N}^{+}$by loss of an $\mathrm{H}$ atom from the initial adduct. Moreover, these primary product ions react further with CRN (Table 3). An alternation of the type of product ion is well-known for small odd and even numbered $\mathrm{C}_{n}{ }^{+}(n<10)^{2}$ and has been observed also for the reactions of larger $\mathrm{C}_{n}{ }^{+}(n>10)$ with arenes. ${ }^{5,6}$ Very likely the electronic configuration varies also in the case of monocyclic cluster radical cations for even and odd numbered $\mathrm{C}_{n}{ }^{++}$. According to theoretical calculation, ${ }^{1 \mathrm{a}, 25}$ neutral monocyclic carbon clusters with an even number of $C$ atoms are closed shell singlets while odd-numbered clusters are open shell triplets, but the corresponding radical cations should be doublets in both cases. However, theoretical calculations ${ }^{70,26-28}$ suggest in addition a polyalkyne structure wtih alternating triple/ single bonds in the ring as the most stable structure for $\mathrm{C}_{18}$ and $\mathrm{C}_{20}$. Very likely the other even numbered clusters have analogous polyalkyne structures, which persist in the corresponding radical cations. A cyclic polyalkyne structure is not possible for the odd numbered clusters and their radical cations but is for large cumulene rings. The different bonding characteristics in even and odd numbered $\mathrm{C}_{n}{ }^{++}$have been suggested to be a likely cause for the different types of product ions from ion $/ \mathrm{molecule} \mathrm{reactions}$ with arenes, ${ }^{6}$ and this may also be true for reactions of $\mathrm{C}_{n}{ }^{++}$with CRN.

The fact that the elimination of $\mathrm{H}$ is observed only for the adducts of $\mathrm{C}_{n}{ }^{++}$with $\mathrm{CRN}$ but not with $\mathrm{ACN}$ is explained plausibly by a loss of $\mathrm{H}$ from the additional methyl group present in CRN. Indeed, the EI mass spectrum of CRN exhibits a large peak of $\mathrm{M}-\mathrm{H}^{+}$fragment ions. However, it is not easy to understand why this elimination of an $\mathrm{H}$ (and $\mathrm{HCN}$ for $n=10$ ) is only possible from the adduct ions of $\mathrm{CRN}$ with even numbered $\mathrm{C}_{n}{ }^{++}$. An electrophilic addition of the carbenium ion center of $\mathrm{C}_{n}{ }^{++}$to the nucleophilic $\mathbf{N}$ atom of the nitrile which has been proposed for the reaction of the fullerene ions $\mathrm{C}_{60} 0^{++}$and $\mathrm{C}_{60}{ }^{2+}$ with $\mathrm{NH}_{3}$, methylamines, and other nucleophiles ${ }^{29}$ could initiate the loss of $\mathrm{H}$ from the methyl group of the attached CRN, but this should occur independently of an odd or even number of $\mathrm{C}$ atoms in $\mathrm{C}_{n}{ }^{++}$. Therefore, it is likely that the even/odd variations of monocyclic $\mathrm{C}_{n}{ }^{++}$reactivity toward $\mathrm{CRN}$ arises from the different structures of odd and even numbered $\mathrm{C}_{n}{ }^{+}$, that is polyalkyne and cumulene structures, respectively.

Tentative Reaction Mechanisms. To explain the effect of different double bond distributions on the reaction of $\mathrm{C}_{n}{ }^{+}$, the mechanisms depicted in Scheme $2 \mathrm{a}, \mathrm{b}$ for $\mathrm{C}_{12}{ }^{\circ+}$ and $\mathrm{C}_{13}{ }^{\circ}$, respectively, are suggested.

The activated collision complex, formed by the electrostatic interaction between $\mathrm{C}_{n}{ }^{+}$and $\mathrm{CRN}$, is converted into a covalently bonded adduct ion $\mathrm{C}_{n+4} \mathrm{H}_{3} \mathrm{~N}^{\circ+}$ (Scheme 2a,b) and stabilized by radiative emission. Although the initial point of attack of the radical cation $\mathrm{C}_{n}{ }^{++}$may be the lone pair of the nitrogen atom of the nitrile group (see the reactions of $\mathrm{C}_{n}{ }^{++}$with $\mathrm{HCN}^{4 a}$ and acetonitrile ${ }^{24}$ ), it is suggested that bonding of ACN and CRN occurs eventually by 1,4 addition to the $\alpha, \beta$-unsaturated nitrile, followed by a $\mathrm{H}$ shift to generate bicyclic adduct ions $\mathrm{a}_{\mathrm{g}}$ and $\mathrm{a}_{\mathrm{u}}$. These bicyclic adduct ions $a_{g}$ and $a_{u}$ may regenerate the original $\mathrm{C}_{n}{ }^{++}$on CID or decompose by fragmentation of the other carbon ring by loss of $\mathrm{C}_{3}$ fragments. However, because of the different distribution of bonds and $\pi$-electrons in even and odd numbered $\mathrm{C}_{n}{ }^{++}$the structures of $\mathrm{a}_{\mathrm{g}}$ and $\mathrm{a}_{\mathrm{u}}$ typically are different. Only in the case of $\mathrm{a}_{\mathrm{g}}$ (even numbered $\mathrm{C}_{12}{ }^{\circ+}$, Scheme $2 \mathrm{a}$ ) does the addition occur across a triple bond of the cluster ion resulting eventually in a bicyclic pyridine structure. The loss of $\mathbf{H}$ from the methyl substituent of this aromatic $\mathrm{C}_{n+4} \mathrm{H}_{5} \mathrm{~N}^{+}$ion creates an (aza)benzylic 
SCHEME 2: Mechanism for the reactions of $C R N$ with Carbon Cluster Ions (a) $C_{12}{ }^{++}$(Even Numbered $C_{n^{++}}$) and (b) $\mathrm{C}_{13^{\circ+}}$ (Odd Numbered $\mathrm{C}_{n}{ }^{+}$) and (c) Mechanism for the Formation of Product Ion $\mathrm{C}_{13} \mathrm{H}_{4}+$ during Reaction of $\mathrm{C}_{10}{ }^{++}$and CRN

a)

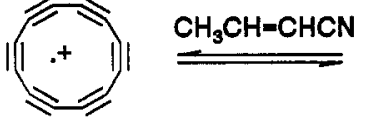

$C_{12}{ }^{+}(m / 2$ 144)

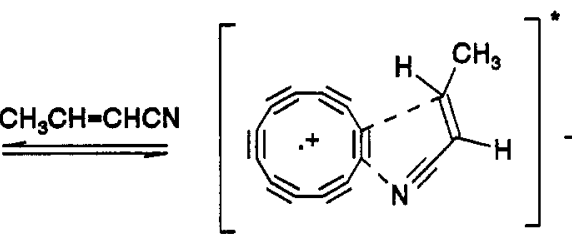

colllsion complex

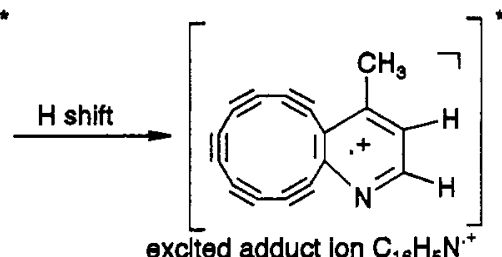

exclied adduct ion $\mathrm{C}_{16} \mathrm{H}_{5} \mathrm{~N}^{-}$ (excited $\mathbf{a}_{0}$ )
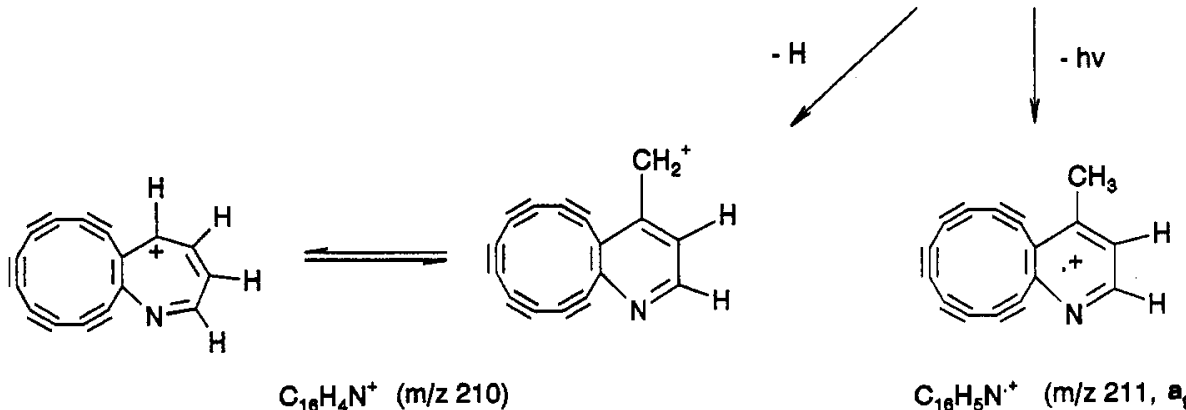

$\mathrm{C}_{10} \mathrm{H}_{5} \mathrm{~N}^{+}\left(\mathrm{m} / \mathrm{z} 211, \mathrm{a}_{\mathrm{g}}\right)$

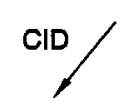

$\mathrm{CH}_{3} \mathrm{CH}-\mathrm{CHCN}$

CID

$\mathrm{C}_{3} \mathrm{H}_{3}{ }^{+}$

secondary products

$\mathrm{C}_{12}{ }^{+}\left(+\mathrm{HCN}+\mathrm{C}_{3} \mathrm{H}_{4}\right)$

b)

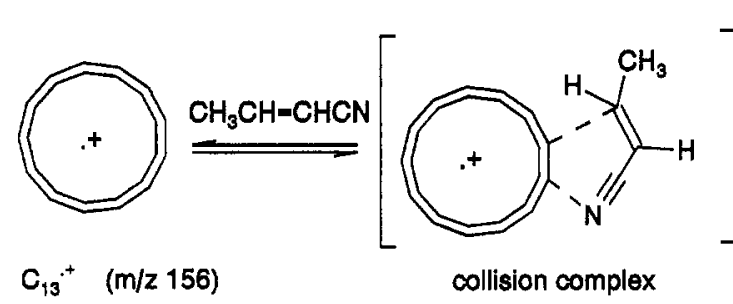

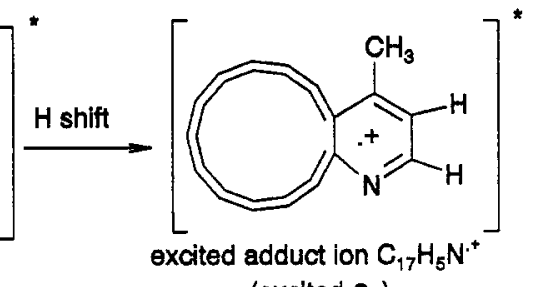
(excled $a_{u}$ )
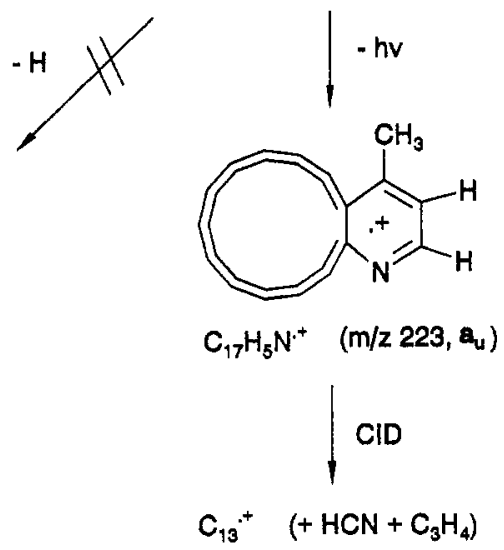

carbenium ion. Benzyl cations react readily with alkenes. Thus, this mechanism and the structure of the $\mathrm{C}_{n+4} \mathrm{H}_{4} \mathrm{~N}^{+}$ions afford a rationale for the secondary reactions of $\mathrm{C}_{n+4} \mathrm{H}_{4} \mathrm{~N}^{+}$with CRN. It is evident that an analogous loss of $\mathrm{H}$ and subsequent secondary reactions are not possible for adduct ions generated by a 1,4 additions of $\mathrm{ACN}$ to $\mathrm{C}_{n}{ }^{++}$. In view of the ubiquitous generation of $\mathrm{C}_{3} \mathrm{H}_{3}+$ ions in the mass spectra of aromatic and heteroaromatic precursors, the generation of this ion by CID of $\mathrm{C}_{n+4} \mathrm{H}_{4} \mathrm{~N}^{+}$ions containing the azabenzyl moiety is plausible.

In contrast to the addition of CRN to even numbered $\mathrm{C}_{n}{ }^{+}$, the cycloaddition product $\mathrm{a}_{u}$ of odd numbered $\mathrm{C}_{n}{ }^{++}$(Scheme $2 \mathrm{~b}$ ) cannot easily acquire a stable pyridine structure but forms a 2,3-dihydropyridine moiety. Hence, the driving force for the elimination of $\mathrm{H}$ from a methyl substituent at an aromatic ring is missing. Instead, stabilization by IR emission and, alternatively, ring opening of the bicyclic adduct ion by cleavage of the central single bond to generate a larger monocyclic ion are likely. This macrocyclic ion is not expected to be reactive toward CRN any more.

\section{Conclusion}

The results of this study of the formation of carbon cluster ions $\mathrm{C}_{n}{ }^{++}(n=10-20)$ by electron impact induced dehalogenation of certain polycyclic perchloroarenes and their reaction with CRN again give no indication of a formation of isomeric clusters $\mathrm{C}_{n}{ }^{0+}$ with different reactivities. Thus, it is proposed that the $\mathrm{C}_{n}{ }^{+}+$are generated by this method in their most stable monocyclic 
structures in spite of the polycyclic carbon skeleton of the precursors. Indeed, the AM1 analysis of the fragmentation of the octachloronaphthalene radical cation by successive $\mathrm{Cl}$ eliminations shows that a formation of monocyclic fragment ions by a retro-Bergman cyclization is energetically favored. Similar processes can be used to explain the formation of other large monocyclic $\mathrm{C}_{n}{ }^{++}$from other polycyclic perchloroarenes.

The ion/molecule reactions of $\mathrm{C}_{n}{ }^{++}$with CRN studied by FTICR spectrometry exhibit new details of the reactivity of medium sized and ionized carbon clusters. (i) Generally, the rate constants are distinctly larger than those for the reactions with $\mathrm{ACN}$ or other nitriles. (ii) Similar to the reactions with $\mathrm{ACN}$ the reaction efficiencies depend inversely on the thermodynamic stability of the $\mathrm{C}_{n}{ }^{\circ+}$. Thus, a particularly high reactivity is observed for the probably anti-aromatic cluster ions $\mathrm{C}_{13}{ }^{\circ+}$ and $\mathrm{C}_{17}{ }^{\circ+}$. (iii) No reactions could be detected for $\mathrm{C}_{n}{ }^{++}$with $n=14-16,18$, and 20; the other $\mathrm{C}_{n}{ }^{++}$yield adduct ions $\mathrm{C}_{n+4} \mathrm{H}_{5} \mathrm{~N}^{\circ+}$ by radiative stabilization. On CID the adduct ions either regenerate $\mathrm{C}_{n}{ }^{++}(n$ $=11,13)$ or eliminate $C_{3}(n=17)$. (iv) Only even numbered $\mathrm{C}_{n}{ }^{++}$yield product ions by loss of $\mathrm{H}$ from the adduct $\mathrm{C}_{n+4} \mathrm{H}_{5} \mathrm{~N}^{*+}$. The $\mathrm{C}_{n+4} \mathrm{H}_{4} \mathrm{~N}^{+}$ions formed react again with CRN.

With respect to reactivity and the type of reaction products, the $\mathrm{C}_{n}{ }^{\bullet+}$ exhibit a rather individual behavior, obviously depending both on thermodynamic stability and on other particulars of the cluster structure. This dependence of reactivity can be perceived by assuming adduct ion formation by a 1,4 cycloaddition of $\alpha, \beta$ unsaturated nitriles to monocyclic $\mathrm{C}_{n}{ }^{++}$(Scheme 2). By this reaction model the increased reactivity toward CRN (compared to $A C N$ ) arises mainly from the lower IE of CRN, reducing the IE gap between the $C_{n}$ and the unsaturated nitrile. Most important, however, for understanding the interesting alternation of reaction products of odd and even numbered $\mathrm{C}_{n}{ }^{++}$are the different bond arrangements in these carbon clusters. The most stable structure of even numbered monocyclic $\mathrm{C}_{n}{ }^{\circ+}$ corresponds to a polyalkyne with alternating single and triple bonds while odd numbered $\mathrm{C}_{n}{ }^{++}$are monocyclic cumulenes. Only the $1,4 \mathrm{cy}-$ cloaddition of CRN across a triple bond results eventually in an ionized bicyclic pyridine derivative which may lose a $\mathrm{H}$ atom from the methyl substituent to generate a reactive azabenzyl cation. According to this picture of the ion/molecule reactions of $\mathrm{C}_{n}{ }^{++}$with the unsaturated nitriles $\mathrm{ACN}$ and CRN, the medium sized carbon clusters can be visualized as reactive organic molecules. It is of interest to test this postulate by studying the reaction of the ionized carbon clusters with other unsaturated substrates, and in a following paper we will discuss the results of the reaction with isomeric chloropropenes to further illustrate this point.

Acknowledgment. This research was supported by a grant from GIF, the German-Israeli Foundation for Scientific Research and Development. H.-F.G. wishes to thank the Deutsche Forschungsgemeinschaft for the gift of the FT-ICR mass spectrometer used for this research.

\section{References and Notes}

(1) For reviews see: (a) Weltner, W., Jr.; van Zee, R. J. Chem. Rev. 1989, 89, 1713. (b) Schwarz, H. Angew. Chem. 1991, 104, 301; Angew. Chem. Int. Ed. Engl. 1991, 31, 183. (c) Several articles in: Acc. Chem. Res. 1992, 25, No. 3.

(2) (a) McElvany, S. W. J. Chem. Phys. 1988, 89, 2063. (b) McElvany, S. W.; Dunlap, B. I.; O'Keefe, A. J. Chem. Phys. 1987, 86, 715.

(3) Bohme, D. K.; Wlodek, S.; Williams, L.; Forte, L.; Fox, A. J. Chem. Phys. 1987, 87, 6934

(4) (a) Parent, D. C.; McElvany, S. W. J. AM. Chem. Soc. 1989, III, 2393. (b) Parent, D. S.; McElvany, S. W. Z. Phys. D: At., Mol., Clusters $1989,12,567$.

(5) Dunbar, R. C.; Pozniak, B. Presented at the 2nd European Workshop on FT-ICR Spectrometry, Antwerp, Belgium, September 7-9, 1993.

(6) (a) Zimmerman, J. A.; Creasy, W. R. J. Chem. Phys. 1992, 96, 1942. (b) Zimmerman, J. A.; Creasy, W. R. J. CHem. Phys. 1991, 95, 3267.

(7) (a) van Zee, R. J.; Ferante, R. F.; Zeringue, K. J.; Weltner, W., Jr. J. Chem. Phys. 1988, 88, 3465. (b) Raghavachari, K.; Binkley, J. S. J. Chem. Phys. 1987, 87, 2191. (c) Parasuk, V.; Almlöf, J.; Feyereisen, M. W. J. Am. Chem. Soc. 1991, 113, 1049. (d) Bernholc, J.; Phillips, J. C. Phys. Rev. B 1986, 33, 7395.

(8) (a) von Helden, G.; Hus, M.-T.; Kemper, P. R.; Bowers, M. T. J. Chem. Phys. 1991, 95, 3835. (b) von Helden, G.; Gotts, N. G.; Bowers, M. T. J. Am. Chem. Soc. 1993, 115, 4363.

(9) Sun, J.; Grützmacher, H.-Fr.; Lifshitz, C. J. Am. Chem. Soc. 1993, 115,8382 .

(10) Bach, S. B. H.; Eyler, J. R. J. Chem. Phys. 1990, 92, 358.

(11) Kofel, P.; Allemann, M.; Kellerhals, Hp.; Wanczek, K. P. Int. J. Mass Spectrom. Ion Processes 1985, 65, 97.

(12) Allemann, M.; Kellerhals, Hp.; Wanczek, K. P. Int.J. Mass Spectrom. Ion Phys. 1993, 46, 139.

(13) Sun, J.; Grützmacher, H.-F.; Lifshitz, C. To be published.

(14) Dewar, M. J. S.; Zöbisch, E. G.; Healy, E. F.; Stewart, J. J. P. J. Am. Chem. Soc. 1985, 107, 3902.

(15) Bergman, R. G. Acc. Chem. Res. 1973, 6, 25

(16) Lifshitz, C.; Sandler, P. Grützmacher, H.-Fr.; Sun, J.; Schwarz, H.; Weiske, T. J. Phys. Chem. 1993, 97, 6592.

(17) Sowa, M. B.; Hitz, P. A.; Anderson, S. L. J. Chem. Phys. 1991, 95, 4719.

(18) (a) Anicich, V. G.; Sen, A. D.; Huntress, W. T., Jr.; McEwan, M. J. J. Chem. Phys. 1991, 94, 4189. (b) Herbst, E. Astrophys. J. 1985, 291, 226.

(19) (a) Dunbar, R. C. J. Phys. Chem. 1987, 91, 2801. (b) Dunbar, R. C. J. Chem. Phys. 1989, 91, 6080.

(20) Dunbar, R. C.; Chen, J. H.; So, H. Y.; Asamoto, B. J. Chem. Phys. $1987,86,2081$.

(21) Lias, S. G.; Bartmess, J. E.; Liebman, J. F. J. Phys. Chem. Ref. Data 1988, Suppl. No. 1, 6174.

(22) Shaik, S. S.; Pross, A. J. Am. Chem. Soc. 1989, 111, 4306.

(23) (a) Thölmann, D.; Grützmacher, H.-F.; J. Am. Chem. Soc. 1991 113, 3281. (b) Thölmann, D.; Grützmacher, H.-F. Int. J. Mass Spectrom. Ion Processes 1992, 117, 415.

(24) Sun, J.; Grützmacher, H.-F.; Lifshitz, C. To be published.

(25) (a) Pitzer, K. S.; Clementi, E. J. Am. Chem. Soc. 1959, 81, 4477. (b) Hoffman, R. Tetrahedron 1966, 22, 521. (c) Strickler, S. J.; Pitzer, K. S. In Molecular Orbitals in Chemistry, Physics, and Biology; Lowdin, P., Pullman, B., Eds.; Academic Press: New York, 1964 (see also references cited therein).

(26) Feyereisen, M.; Gutowski, M.; Simons, J. J. Chem. Phys. 1992,.96, 2926.

(27) Diedrich, F.; Rubin, Y.; Knobler, C. B.; Whetten, R. L.; Schriver, K. E.; Houk, K. N. Science 1989, 245, 1088.

(28) Parasuk, V.; Almlof, J. Chem. Phys. Lett. 1991, 184, 187.

(29) (a) Petrie, S.; Javahery, G.; Wang, J.; Bohme, D. K. J. Am. Chem. Soc. 1992, 114, 9177 . (b) Petrie, S.; Javahery, G.; Bohme, D. K. J. Am. Chem. Soc. 1993, 115, 1445 . 